\title{
PENYUSUNAN RENCANA STRATEGIS SISTEM INFORMASI DAN TEKNOLOGI INFORMASI (SI/TI) ORGANISASI BISNIS STKIP MUHAMMADIYAH KOTABUMI MENGGUNAKAN WARD PEPPARD
}

\author{
Sigit Gunanto ${ }^{1}$, Nisar ${ }^{2}$ \\ ${ }^{123}$ Fakultas Magister Teknik Informatika, Institut Informatika dan Bisnis Darmajaya \\ Jl. 2.A. Pagar Alam No. 93, Bandar Lampung - Indonesia 35142 \\ Telp. (0721) 787214 Fax. (0721) 700261 \\ e-mail : sigitgunanto@gmail.com,
}

\begin{abstract}
Information systems contribute to improving the quality of education services, operational efficiency and organizational business support. The use of information systems and information technology in a variety of teaching and learning process activities in an educational institution is not something that is complementary and additional, but a need in improving the process and the results of educational implementation of universities, therefore it is necessary to manage the information by building a system Information (SI) and supported by good and planned Information Technology (IT) to become a new strength for institutions in maintaining and increasing competitiveness. The Ward and Peppard method is a widely used model for preparing a strategic planning of an information system in an organization. With this method, various factors affecting both internal and external organizations are analyzed in such a way as to derive a new strategy. Research conducted in STKIP Muhammadiyah Kotabumi, data collection is done by doing interviews, observation and review documents. The results of this study is a strategic plan that can be poured in a portfolio that can be used as reference information system planning in STKIP Muhammadiyah Kotabumi.
\end{abstract}

Keywords $\quad$ : Analysis of SI / IT, Ward and Peppard Method, and Strategic Planning STKIP Muhammadiyah Kotabumi.

\begin{abstract}
ABSTRAK
Sistem informasi berkontribusi meningkatkan kualitas pelayanan pendidikan, efisiensi operasional dan penunjang bisnis organisasi. Penggunaan sistem informasi dan teknologi informasi dalam berbagai kegiatan proses belajar mengajar pada suatu institusi pendidikan bukanlah sesuatu hal yang bersifat pelengkap dan tambahan, melainkan suatu kebutuhan dalam meningkatkan proses maupun hasil pelaksanaan pendidikan yang dilakukan perguruan tinggi, karena itu diperlukan pengelolaan informasi tersebut dengan membangun sebuah Sistem Informasi (SI) dan didukung Teknologi Informasi (TI) yang baik dan terencana sehingga menjadi sebuah kekuatan baru bagi institusi dalam memelihara dan sekaligus meningkatkan daya saing. Metode Ward and Peppard merupakan sebuah model yang digunakan secara luas bagimana sebuah perencanaan strategik sistem informasi pada sebuah organisasi/perusahaan. Dengan metode ini, berbagai faktor yang berpengaruh terhadap organisasi baik internal maupun eksternal dianalisis sedemikian rupa untuk
\end{abstract}


mendapatkan sebuah strategi baru. Penelitian dilakukan di STKIP Muhammadiyah Kotabumi, pengumpulan data dilakukan dengan cara melakukan wawancara, observasi dan mengkaji dokumen. Hasil penelitian ini merupakan rencana strategis yang dapat dituangkan dalam portofolio yang dapat digunakan sebagai acuan perencanaan sistem informasi di STKIP Muhammadiyah Kotabumi.

Kata Kunci $\quad$ : Analisis SI/TI, Metode Ward and Peppard, dan Perencanaan Strategik STKIP Muhammadiyah Kotabumi.

\section{PENDAHULUAN}

Perencanaan dan penerapan SI/TI merupakan suatu yang harus dimiliki serta di implementasikan dalam institusi pendidikan khususnya perguruan tinggi. Berangkat dari hal tersebut,ternyata masih banyak institusi pendidikan yang belum dapat menerapkan dan menjadikan SI/TI sebagai alat untuk menjadikan unggul dalam persaingan. Untuk pencapaian visi dan misi perguruan tinggi peran serta SI/TI sangat dibutuhkan, sehingga pemanfaatan dan infrastruktur SI/TI menjadi suatu alat yang dapat digunakan sebagai penunjang proses dan strategi untuk mencapai tujuan, pencapaian visi dan misi serta menjalankan Tri dharma perguruan tinggi. Penggunaan dan penerapan SI/TI akan membawa nilai tambah bagi keunggulan kompetitif institusi itu sendiri.

STKIP Muhammadiyah Kotabumi saat ini, dalam pemanfaatan dan penggunaan SI/TI masih sangat terbatas, hal demikian membawa dampak bagi kegiatan akademik. Pada masa perkembangan informasi seperti sekarang, kemudahan informasi untuk mendukung kebutuhan akademik merupakan sesuatu yang sangat penting, tetapi dengan kurangnya perencanaan dan penerapan SI/TI akses informasi menjadi sangat sulit serta sumber belajar sangat minim. Kurangnya sumber informasi dan sulit dalam memenuhi kebutuhan informasi akademik merupakan kondisi STKIP Muhammadiyah Kotabumi saatini. Hal yang sama juga terjadi terhadap kegiatan pendukung akademik itu sendiri, seperti administrasi dan kepegawaian. Data dan informasi dari setiap bagian dan unit kerja tidak terdistribusi dengan baik dan belum tersentralisasi.

Keselarasan strategi penerapan SI/TI dengan proses bisnis merupakan suatu keharusan agar penerapan SI/TI dapat berjalan secara sinergi dan memberikan manfaat bagi organisasi. Penyusunan rencana strategis SI/TI perlu dilakukan agar terjadi perencanaan pembangunan, pengembangan dan implementasi sistem aplikasi dan teknologi yang terintegrasi 
serta selaras dengan proses bisnis organisasi, kemampuan bersaing dalam penerapan SI/TI yang baik. Pada saat ini STKIP Muhammadiyah Kotabumi belum memiliki roadmap perencanaan, pengembangan serta fasilitas SI/TI yang terintegrasi, sehingga penyusunan rencana strategis SI/TI perlu dilakukan untuk menterjemahkan visi dan misi STKIP Muhammadiyah Kotabumi kedalam kebutuhan Sistem Informasi dan Teknologi Informasi, serta pengembangan dan implementasi SI/TI secara berkelanjutan.

Perencanaan strategis SI/TI juga mempelajari pengaruh SI/TI terhadap kinerja bisnis dan konstribusi bagi organisasi dalam memilih langkah-langkah strategis. Selain itu perencanaan strategis SI/TI juga menjelaskan berbagai tools, teknik dan kerangka kerja bagi manajemen untuk memberikan keselarasan antara strategi SI/TI dengan strategi bisnis, bahkan mencari kesempatan baru melalui penerapan teknologi inovatif [1].

Perencanaan strategis SI/TI merupakan proses identifikasi portofolio aplikasi SI berbasis komputer yang akan mendukung organisasi dalam pelaksanaan rencana bisnis dan merealisasikan tujuan bisnisnya. Perencanaan strategis SI/TI mempelajari pengaruh SI/TI terhadap kinerja bisnis dan kontribusi bagi organisasi dalam memilih langkah-langkah strategis. Selain itu, perencanaan strategis SI/TI juga menjelaskan berbagai tools, teknik, dan kerangka kerja bagi manajemen untuk menyelaraskan strategi SI/TI dengan strategi bisnis, bahkan mencari kesempatan baru melalui penerapan teknologi yang inovatif [1]. Beberapa karakteristik dari perencanaan strategis SI/TI antara lain adalah adanya misi utama. Keunggulan strategis atau kompetitif dan kaitannya dengan strategi bisnis; adanya arahan dari eksekutif atau manajemen senior dan pengguna serta pendekatan utama berupa inovasi pengguna dan kombinasi pengembangan bottom up dan analisa top down.

\section{METODE PENELITIAN}

Metodologi yang digunakan adalah ward and peppard, dalam penelitian ini akan digunakan kerangka pemikiran berupa pengumpulan data melalui observasi dan wawancara, analisa lingkungan bisnis organisasi eksternal dilakukan dengan analisis PEST (Politik, Ekonomi, Sosial Budaya dan kemajuan Teknologi) untuk mendapatkan identifikasi peluang bisnis dari eksternal organisasi, kemudian analisa lingkungan bisnis organisasi internal dilakukan dengan menggunakan analisis Critical Success Factor, analisis SWOT, dan analisis Value Chain untuk mendapatkan identifikasi masalah internal bisnis, selanjutnya analisa lingkungan 
SI/TI eksternal untuk identifikasi perkembangan teknologi dan kebutuhan teknologi yang ada saat ini untuk mengetahui aplikasi terkini saat ini dan analisa lingkungan SI/TI internal dalam rangka mendapatkan identifikasi sumber daya SI/TI untuk mengetahui aplikasi portofolio saat ini.

Selanjutnya analisa GAP kebutuhan informasi untuk membuat landasan kebijakan SI/TI serta membuat strategi SI/TI berupa strategi manajemen SI/TI, strategi bisnis SI/TI dan strategi SI/TI yang akan didapatkan hasil akhir berupa aplikasi portofolio mendatang.

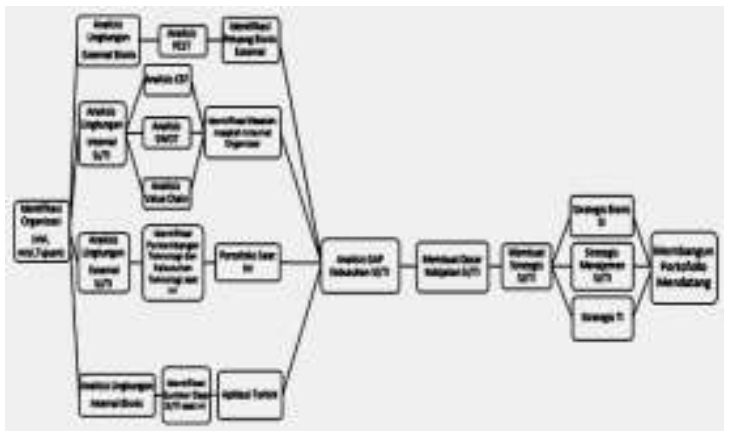

Gambar 1. Kerangka Kerja Perencanaan SI/TI

\section{HASIL DAN PEMBAHASAN}

Penyusunan rencana strategi pada penelitian ini menggunakan pendekatan Ward and Peppard. Tahapan yang dimiliki oleh Ward and Peppard terdapat rencana strategi TI, di dalam tahapan tersebut penyusyn renstra. Penelitian ini berisi suatu bentuk organisasi secara global yang empunyai rencan bisnis berisi misi, visi, tujuan, dan sasaran. Untuk mempertahankan bisnis yang sudah berjalan dan untuk mendapatkan kemampuan bersaing dengan pesaingnya, organiasi ingin membuat rencan strategi SI/TI. Menyusun strategi SI/TI berdasarkan hasil evaluasi serta analisis sehingga diperoleh adanya peluang-peluang dan kesempatan dari suatu kendala yang dipahami. Agar rencana strategi ini dapat dibuat dengan baik maka diperlukan suatu alur kerja perencanaan strategi SI/TI dan dapat diimplementasikan dalam suatu organisasi dengan budaya yang baik dan terencana sehingga menjadi sebuah kekuatan baru bagi institusi dalam memelihara dan sekaligus meningkatkan daya saing.

\subsection{Analisis PEST (Politik, Ekonomi,} Sosial dan Teknologi)

Berbagai faktor eksternal berpengaruh terhadap aktivitas sebuah perusahaan baik langsung maupun tidak langsung, seperti faktor politik, ekonomi, sosial dan budaya. Dengan mengenali dan mengevaluasi peluang dan ancaman eksternal, perusahaan akan mampu mengembangakan visi dan misi sebagai dasar strategi yang tepat untuk mencapai sasaran jangka panjang. Berikut hasil analisis PEST pada STKIP Muhammadiyah Kotabumi

Tabel 1. Analisis PEST terhadap STKIP Muhammadiyah Kotabumi

\begin{tabular}{|l|l|ll|}
\hline No & $\begin{array}{l}\text { Analisis } \\
\text { PEST }\end{array}$ & Implikasi & \\
\hline 1. & Faktor & 1.1 Sistem & Pendidikan \\
\hline
\end{tabular}




\begin{tabular}{|c|c|c|}
\hline & Politik & 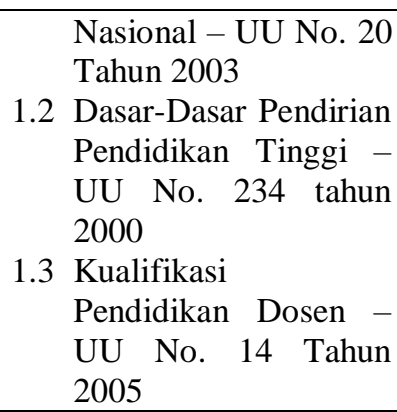 \\
\hline 2. & $\begin{array}{l}\text { Faktor } \\
\text { Ekonomi }\end{array}$ & $\begin{array}{l}\text { Pertumbuhan tingkat } \\
\text { kemiskinan } \\
\text { mempengaruhi } \\
\text { penurunan daya beli } \\
\text { masyarakat di bidang } \\
\text { pendidikan. Hal ini } \\
\text { harus ditanggapi oleh } \\
\text { STKIP } \\
\text { Muhammadiyah } \\
\text { Kotabumi dengan cara } \\
\text { memberikan beasiswa } \\
\text { kepada mahasiswa } \\
\text { tidak mampu yang } \\
\text { mempunyai prestasi } \\
\text { secara akademik } \\
\text { maupun non } \\
\text { akademik. }\end{array}$ \\
\hline 3. & $\begin{array}{l}\text { Faktor } \\
\text { Sosial }\end{array}$ & $\begin{array}{lr}\text { Faktor-faktor } & \text { sosial } \\
\text { terpusat } & \text { pada } \\
\text { penilaian dari sikap } \\
\text { konsumen } \\
\text { karyawan dan } \\
\text { mempengaruhi } \\
\text { strategi. Faktor-faktor } \\
\text { sosial yang dianalisi } \\
\text { dan diagnosis oleh } \\
\text { kebanyakan organisasi } \\
\text { antara lain : Distribusi } \\
\text { pendapatan, } \\
\text { demografi, tenaga } \\
\text { kerja/mobilitas sosial, } \\
\text { perubahan gaya hidup, } \\
\text { sikap } \\
\text { pendidikan, kesehatan, } \\
\text { kesejahteraan. }\end{array}$ \\
\hline 4. & $\begin{array}{l}\text { Faktor } \\
\text { Teknolog } \\
\text { i }\end{array}$ & $\begin{array}{l}\text { Web kampus sebagai } \\
\text { media teknologi dan } \\
\text { informasi yang } \\
\text { merupakan bagian } \\
\text { strategi marketing. }\end{array}$ \\
\hline
\end{tabular}

\subsection{Analisis Lingkungan Internal \\ Bisnis}

Analisis lingkungan internal bisnis dapat dilakukan dengan menggunakan Metode Analisis CSF, SWOT dan Value Chain. Analisis pada tahap ini merupakan tahapan penting dalam perencanaan strategik SI/TI karena menentukan cakupan perencanaan strategik SI/TI dan memberikan dasar bagi perumusan strategi SI/TI. Analisis ini akan membantu pemahaman tentang kondisi lingkungan organisasi dengan melihat dampak dan potensi SI/TI terhadap pelaksanaan tugas pokok dan fungsi kampus sebagai institusi pendidik khususnya di STKIP Muhammadiyah Kotabumi. Dengan mengidentifikasi kebutuhan SI/TI serta peluang yang timbul diharapkan dapat disusun prioritas kebutuhan dan penggunaan SI/TI untuk mendukung pencapaian strategi organisasi. Kegiatan analisis meliputi kondisi lingkungan proses dan kondisi SI/TI baik dilihat dari sisi internal organisasi.

\subsubsection{Analisis Critical Success Factor (CSF)}

Kegiatan ini akan dielaborasikan visi dan misi menjadi tujuan bisnis dari STKIP Muhammadiyah Kotabumi yang kemudian akan diaplikasikan menggunakan CSF 
analisis untuk menemukan kebutuhan TIK dari organisasi.

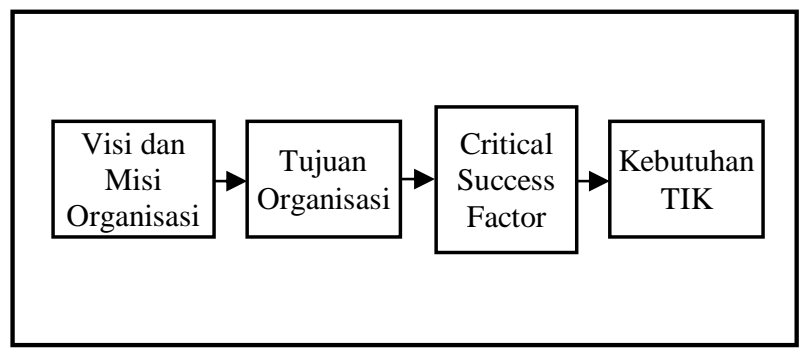

Gambar 2. Langkah-Langkah Elaborasi Tujuan Organisasi

\subsubsection{Analisis SWOT (Strength, Weaknes, Opportunities, dan Threat) \\ Analisis untuk mencari strategi} dengan menggunakan kekuatan yang ada untuk memanfaatkan peluang yang tersedia (strategi S-O) serta menggunakan kekuatan yang dimiliki untuk mengatasi ancaman yang ada (strategi S-T). Selain itu dianalisis pula strategi untuk mengurangi kelemahan yang dimiliki dalam meraih peluang yang ada (strategi W-O) maupun mengatasi ancaman yang ada (strategi $\mathrm{W}$ T). Pemetaan strategi S-O, W-O, S-T dan W-T dapat dilihat pada tabel di bawah ini

\section{Tabel 2. Strategi S-O}

\begin{tabular}{|c|c|}
\hline Faktor Eksternal & $\begin{array}{l}\text { Strengths (S) } \\
\text { 1. Memiliki visi, misi yang sesuai } \\
\text { dengan visi misi Sekolah Tinggi } \\
\text { 2. Adanya keinginan yang kuat } \\
\text { dari STKIP Mubammadiyah } \\
\text { Kotabumi mengenbangkan } \\
\text { kegiatan pendidikan, penelitian } \\
\text { dan pengabdian pada } \\
\text { masyarakat pada bidang ilma } \\
\text { komputer }\end{array}$ \\
\hline $\begin{array}{l}\text { Opportunities }(\mathbf{O}) \\
\text { 1. Tingginya animo tamatan sekolah } \\
\text { menengah untuk meadalami bidang } \\
\text { teknologi komputer, seiring dengan } \\
\text { pesatnya pertumbuhan Sekolah } \\
\text { menengah Kejuruan Bidang } \\
\text { Teknologi } \\
\text { 2. Persaingan kampus yang membuka } \\
\text { program komputer belum banyak }\end{array}$ & $\begin{array}{l}\text { StrategiS-O } \\
\text { Dengan visi dan misi yang jelas } \\
\text { dan keinginan yang kuat untuk } \\
\text { melaksanakan Tri Dharma } \\
\text { Perguruan Tinggi dalam upaya } \\
\text { mencerdaskan kebidupan bangsa }\end{array}$ \\
\hline
\end{tabular}

\section{Tabel 3. Strategi S-T}

\begin{tabular}{|c|c|}
\hline Faktor Eksternal & $\begin{array}{l}\text { Strengths (S) } \\
\text { 1. Memiliki visi, misi yang sesuai } \\
\text { dengan visi misi Sekolah Tinggi } \\
\text { 2. Adanya keinginan yang kuat } \\
\text { dari STKIP Mahammadivah } \\
\text { Kotabumi mengembangkan } \\
\text { kegiatan pendidikan penelitian } \\
\text { dan pengabdian pada } \\
\text { masyarakat pada bidang ilmu } \\
\text { komputer }\end{array}$ \\
\hline $\begin{array}{l}\text { Threats (T) } \\
\text { 1. Tuntutan penyediaan sarana dan } \\
\text { prasana yang lengkap dan } \\
\text { representative } \\
\text { 2. Tuntutan kesejahteraan yang lebih } \\
\text { tingo bagi dosen }\end{array}$ & $\begin{array}{l}\text { StrategiS-T } \\
\text { Peningkatan sarana dan prasarana } \\
\text { dalam rangka terlaksananya proses } \\
\text { belajar mengajar yang kondusif. }\end{array}$ \\
\hline
\end{tabular}

Tabel 4. Strategi W-O

\begin{tabular}{|c|c|}
\hline Faktor I & $\begin{array}{l}\text { Weaknessess (W) } \\
\text { 2. Sarana, prasarasa alkademik } \\
\text { yang beham memadai } \\
\text { Kapasitas Teknologi Informasi } \\
\text { behmmemadai } \\
\text { 3. Kurangrya riset dan penelitian } \\
\text { yang dilakukan mahasiswa das } \\
\text { dosen karema keterbatasan dana } \\
\text { 4. Kerjasama dengan dumia usaha } \\
\text { dan industri masib sangat minim }\end{array}$ \\
\hline Opportminties & Strategi W-O \\
\hline $\begin{array}{l}\text { 1. Tingginya animo tamatan sekolah } \\
\text { menengah untuk mendalani bidang } \\
\text { teknologi konputer, seiring dengan } \\
\text { pesatnya pertumbuhan Selolah } \\
\text { menengah Kejuruan Bidang } \\
\text { Telnologi } \\
\text { 2. Persaingan kannus yang membuka } \\
\text { program komnuter belum banyak }\end{array}$ & $\begin{array}{l}\text { Peningkatan pengembangan } \\
\text { teknologi informasi yang memadai } \\
\text { dalam ranglka meanberikan } \\
\text { pelayanan yang maksimal terhadap } \\
\text { mabasiswa. }\end{array}$ \\
\hline
\end{tabular}

Tabel 5. Strategi W-T

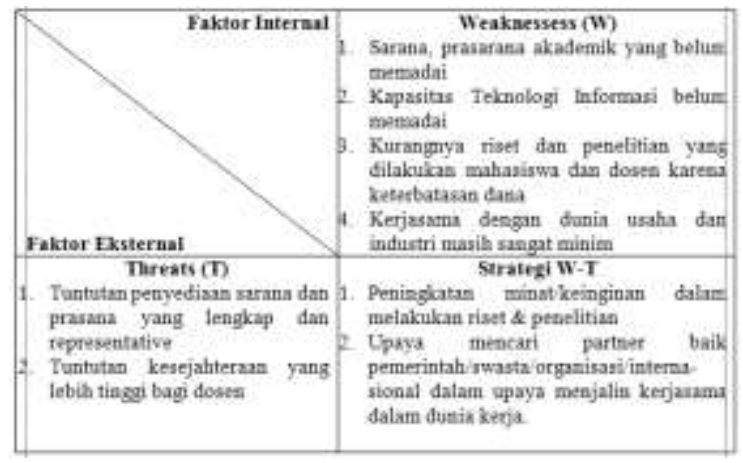

\subsubsection{Analisis Value Chain}

Analisis Value Chain merupakan suatu metode untuk merinci suatu rangkaian dari bahan baku hingga produk akhir yang digunakan, menjadi kegiatan 
strategi yang relevan untuk memahami perilaku biaya dan perbedaan sumber daya. Penerapan Value Chain dalam penyelenggaraan pendidikan tinggi memiliki aktifitas utama yaitu pendidikan, penelitian dan pengabdian pada masyarakat, sesuai dengan Tridarma Perguruan Tinggi. Kegiatan Tridarma Perguruan Tinggi merupakan kegiatan utama yang memerlukan dukungan dari aktifitas lain seperti administrasi mahasiswa, administrasi keuangan, administrasi kepegawaian.

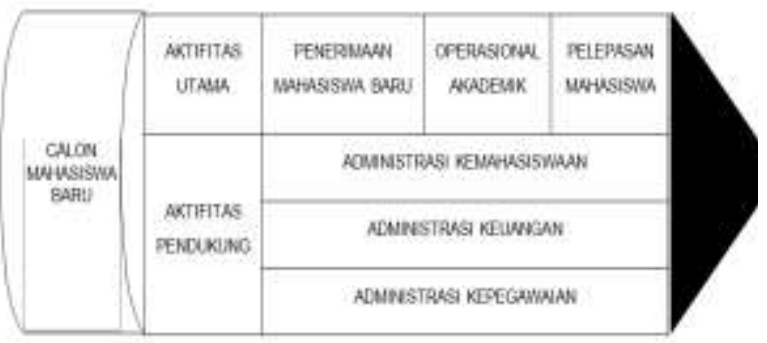

Gambar 3. Aktivitas Value Chain di STKIP Muhammadiyah Kotabumi

\subsubsection{Analisis Mc Farlan's Strategic Grid pada STKIP Muhammadiyah Kotabumi}

Tabel 6. Portofolio SI/TI STKIP Muhammadiyah Kotabumi

\begin{tabular}{|c|c|c|c|}
\hline \multicolumn{2}{|l|}{ STRATEGIC } & HIGH POTENTI & \\
\hline 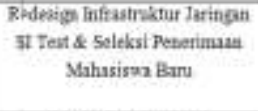 & $\begin{array}{l}\text { Tpgade } \\
\text { Baru }\end{array}$ & $\begin{array}{l}\text { Abeessi Oetiae } \\
\text { E-Leaning } \\
\text { E.Libraby } \\
\text { Tesmologi KJM Manpetic }\end{array}$ & $\begin{array}{l}\text { Barn } \\
\text { Bar: } \\
\text { Bare } \\
\text { Barn }\end{array}$ \\
\hline 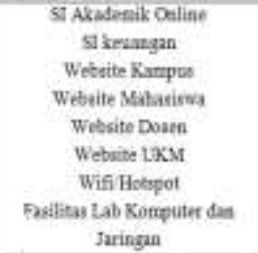 & $\begin{array}{c}\text { Blaru } \\
\text { Baru } \\
\text { Lpgade } \\
\text { Baru } \\
\text { Baru } \\
\text { Baru } \\
\text { Upgande } \\
\text { tipgade }\end{array}$ & $\begin{array}{l}\text { St Jumal Tlmah Coline } \\
\text { st Alumai } \\
\text { Websitt Bsen Lonvagan } \\
\text { Ketje }\end{array}$ & $\begin{array}{l}\text { Bare } \\
\text { Bare } \\
\text { Bars }\end{array}$ \\
\hline \multicolumn{2}{|l|}{ KIY OPERATIONAL. } & SCPPOKT & \\
\hline
\end{tabular}

\section{SIMPULAN}

Hasil atau deliverables dari penyusunan perencanaan strategik SI/TI dengan menggunakan metodologi Ward dan Peppard berupa rancangan portofolio masa yang akan datang yaitu dihasilkan pedoman dalam pelaksanaan pengembangan SI/TI pada STKIP Muhammadiyah Kotabumi dan road map yang memuat tahapan implementasi yang meliputi pengembangan SI/TI yang akan dikembangkan.

\section{DAFTAR PUSTAKA}

[1] John Ward and Joe Peppard. 2002. Strategic Planning for Information System, $3^{\text {rd }}$ ed. John Wiley \& Sons. Chichester: Baffins Lane

[2] Indrajit, E.R. 2004. Kajian Strategis: cost benefit teknologi informasi (panduan investasi pengembangan TI di perusahaan). Yogyakarta: Andi Offset.

[3] Liandi, O., \& Fitria, F. (2019). Evaluasi Tata Kelola Framework COBIT 5 pada Dinas Kependudukan dan Pencatatan Sipil. POSITIF: Jurnal Sistem dan Teknologi Informasi, 5(2), 111115. 